Passagens. Revista Internacional de História Política e Cultura Jurídica, Rio de Janeiro: vol.1 no. 2, julo/dezembro 2009, p. 40-49.

\title{
LOS USOS DE LA DICTADURA EN LA DEMOCRACIA POSDICTADURA Y LAS FORMAS DE DOMINACIÓN POR EL CONSENSO ${ }^{1}$ THE USES OF AUTOCRACY IN THE POST-DICTATORSHIP DEMOCRACY AND FORMS OF DOMINATION THROUGH CONSENSUS
}

\section{DOI: 10.5533/1984-2503-20091203}

\begin{abstract}
Álvaro Rico
RESUMO

Pesquisa sobre a história política recente do Uruguai, particularmente sobre o período ditatorial e as formas de dominação e legitimação da ordem política estatal na democracia pós-ditadura no Uruguai.

Palavras-chave: Uruguai, democracia, dominação, consenso.
\end{abstract}

\section{RESUMEN}

Investigación sobre la historia política reciente del Uruguay, particularmente sobre el período dictatorial y luego sobre las formas de dominación y legitimación del orden político estatal en la democracia posdictadura en Uruguay.

Palabras-clave: Uruguay, democracia, dominación, consenso.

\section{ABSTRACT}

Research on recent political history of Uruguay, particularly covering the dictatorship period and the ways in which the political order of the state dominated and legitimized in the post-dictatorship democracy in Uruguay.

\footnotetext{
${ }^{1}$ Texto apresentado en el Colóquio Internacional Sociabilidades, Poder y Cultura Política: Circulación de ideas y apropiación cultural, Universidad Federal Fluminense (UFF) e Universidad Federal de Rio de Janeiro (UFRJ). Niterói, 27 a 29 de maio de 2009.
} 
Key words: Uruguay, democracy, domination, consensus.

\section{RÉSUMÉ}

Une recherche sur l'histoire politique récente de l'Uruguay, plus particulièrement sur la période dictatoriale et les formes de domination et de légitimation de l'ordre politique étatique dans la démocratie post-dictature en Uruguay.

Mots-clés : Uruguay, démocratie, domination, consensus.

Voy a hacer una intervención que contiene dos partes diferenciadas. Por un lado, trataré de resumir algunas conclusiones de una línea de investigación personal sobre las formas de dominación y legitimación del orden político estatal en la democracia posdictadura en Uruguay ${ }^{2}$.

La segunda parte de mi intervención refiere a la historia política reciente del Uruguay, particularmente sobre el período dictatorial. Se trata de resumir los resultados de dos investigaciones históricas que coordiné durante tres años y medio realizadas para la Presidencia de la República sobre detenidos desaparecidos $^{3}$ y luego para la Universidad de la República sobre la dictadura y el terrorismo de Estado en el Uruguay ${ }^{4}$.

\footnotetext{
${ }^{2}$ RICO, Álvaro. (2005). Cómo nos domina la clase gobernante. Orden político y obediencia social en la democracia posdictadura 1985-2005. Montevideo: Ediciones Trilce.

3 Presidencia de la República. Investigación Histórica sobre Detenidos Desaparecidos. En cumplimiento de la Ley № 15.848. 4 Tomos. Dirección Nacional de Impresiones y Publicaciones Oficiales (IMPO), Montevideo, junio 2007. Ver libro digital: wwwpresidencia.gub.uy

${ }^{4}$ Universidad de la República. Investigación Histórica sobre la dictadura y el terrorismo de Estado en el Uruguay (1973-1985). 3 Tomos. Editorial Cruz del Sur-Comisión Sectorial de Investigación Científica (CSIC)-Centro de Estudios Interdisciplinarios Uruguayos (CEIU)Facultad de Humanidades y Ciencias de la Educación, Montevideo, diciembre 2008 (1aㅡ edición); mayo 2009 ( $2^{\underline{a}}$ edición).
} 
Sobre el primer punto. Pretendí analizar cómo se produjo en el ejemplo uruguayo el pasaje de un tipo de poder: dictatorial (1973-1985), basado fundamentalmente en la fuerza y el miedo a otro tipo de poder: democrático (restaurado desde el año 1985) basado en el consenso y la obediencia voluntaria de la ciudadanía, con un alto poder de socialización, incorporación y circulación de las ideas.

No me propuse una reconstrucción histórica o cronológica acerca de cómo se produjo el tránsito de la dictadura a la democracia y sus etapas sino que utilicé otro enfoque interdisciplinario. En ese sentido, analizo cómo nuestro proceso de transición a la democracia, entre 1980 y 1989, incluyó también una transición discursiva, es decir, una lucha por el significado de la palabra pública y la resignificación de identidades - un ejercicio predominante de violencia simbólica que venía a sustituir la violencia física ejercida directamente sobre los cuerpos por la dictadura.

Dicho de otra manera, la clase gobernante trató de "hacer orden con palabras" (J. Austin), donde los aspectos subjetivos, la capacidad significante de la palabra política, los relatos dominantes, los voceros autorizados potenciados por los medios masivos de comunicación fueron imponiendo determinados signos y símbolos (que estaban en disputa) acerca de lo que era "políticamente correcto" hacer y decir en democracia y que finalmente dotaron de sentido único las explicaciones sobre el pasado dictatorial y quiénes fueron los responsable de la crisis y la dictadura.

A pesar de las sucesivas crisis del capitalismo y las grandes transformaciones políticas experimentadas en el país en el último medio siglo incluida la dictadura- los marcos de referencia explicativos y los límites para pensar esos cambios fueron predeterminados o negados por el "régimen de verdad" que aquellos relatos dominantes instituyeron durante años, apoyándose en los fuertes cambios en la subjetividad social procesados durante (y por) el terrorismo de Estado. De allí que absorbieran las continuas crisis del capitalismo dentro de una explicación racional única y que disciplinaran la pluralidad social posdictadura dentro del orden estatal monopólico, sin grades protestas ni cuestionamientos ciudadanos.

No es que los referentes alternativos, principalmente los de izquierda, desaparecieran o dejaran de significar mediante prohibición alguna (como 
sucedió en la dictadura por medio de ilegalizaciones y censuras) sino que, en buena medida, dejaron de significar: o porque serán desacreditados, excomulgados por el sentido dominante (por decimonónicos, obsoletos) o terminarán girando su propuesta en torno al sentido dominante dentro de un proceso de adopción acrítica del liberalismo por importantes sectores de izquierda.

En ese marco, opera también una "relación conflictiva" de la izquierda con su propio pasado reciente y su reapropiación crítica en los nuevos tiempos democráticos. La izquierda institucional incorpora de su pasado el heroísmo y el martirologio pero no sus responsabilidades respecto a la ruptura institucional ni su relación ambivalente con la democracia. Por otra parte, la izquierda se reorganizó más en clave ciudadana que social, más como partido que como movimiento, haciendo girar su capacidad propositiva en torno a las exigencias de la "agenda estatal", sin capacidad de trascender los sentidos y urgencias del sistema capitalista para su reproducción.

Ahora bien, la aceptación del discurso dominante sistematizado desde el Estado por los políticos profesionales de los partidos tradicionales (1985-2005) no trata de una mera manipulación del poder. Por el contrario, ese proceso se realiza eficazmente en la medida que incorpora voluntariamente a la ciudadanía al sistema: por consenso. Para que ello suceda, los argumentos del poder deben identificarse con las experiencias de vida cotidianas, deben pasar a formar parte de los miedos (sedimentados bajo la dictadura) y de la reapropiación-recreación de creencias y mitos (el "Uruguay de Maracaná", "como el Uruguay no hay", etc.) que dan seguridad y orientan a las personas diariamente, pero ya no como ideologías o discursos políticos estructurados sino como el mero "sentido común" de la democracia restaurada a partir del $1^{\circ}$ de marzo de 1985, es decir, mediante explicaciones obvias, inconexas, estereotipadas, al alcance de la mano, proceso que también coincide con una construcción del campo cultural y de lo popular muy banalizado e inmediatista, a través de la incidencia de los medios masivos de comunicación. De paso, ello permite estigmatizar el sentido "no común" (sesentista, obsoleto) o el "sin sentido" de las posiciones críticas o radicales que, por otra parte, "nada van a cambiar". 
En ese proceso de "naturalización" del statu quo, de rutinización de las relaciones de poder adquiere una dimensión muy importante para recabar la obediencia ciudadana los "usos de la historia" por el discurso político dominante, en particular, de la historia reciente.

Esos "usos de la historia" por el discurso hegemónico en la etapa posdictadura trató de disolver el carácter épico de la historia de los años 1960 y de la lucha contra la dictadura en el consenso apacible y tolerante de las mayorías electorales e imponer la convivencia pacífica entre víctimas y victimarios a partir de la consigna "sin vencidos ni vencedores", que justificaba la impunidad para los responsables en las violaciones a los derechos humanos. El momento culminante desde el punto de vista institucional fue la aprobación parlamentaria (en 1986) de la llamada Ley de Caducidad de la Pretensión Punitiva del Estado y su ratificación plebiscitaria por la ciudadanía (en 1989). Ley que coincide en el tiempo con la caída del "Muro de Berlín", potenciando ambos acontecimientos (nacional e internacional) el proceso de crisis de las utopías y de las alternativas sistémicas al capitalismo.

Esta interpretación de la historia y el papel de los políticos tradicionales impidió, durante 20 años, la no intervención de la justicia en la investigación de las denuncias y procesamiento a los responsables (civiles o militares) de los delitos de lesa humanidad, la imposibilidad de acceder a la documentación sobre el período depositada en los archivos estatales, la estigmatización de quienes denunciaban públicamente los hechos (por "tener los ojos en la nuca" o buscar el "revanchismo"). En síntesis, el olvido institucional sobre los crímenes de Estado y sus agentes responsables. La democracia restaurada careció así de fundamento ético y acentuó su carácter procedimental (como "reglas de juego"), elitizando las instancias de toma de decisión y confirmándose como democracia liberal frente a cualquier aproximación crítica.

Esta situación que estoy someramente describiendo comenzó a cambiar con el triunfo electoral del Frente Amplio en el año 2005, y la asunción del Dr. Tabaré Vázquez como Presidente de la República. A partir de allí, una nueva interpretación de la ley de caducidad por el Poder Ejecutivo habilitó las investigaciones de la justicia ordinaria y el procesamiento, hasta el momento, de 10 militares y policías y 2 civiles, entre ellos, dos dictadores Juan María Bordaberry y el Tte. Gral. Gregorio Álvarez. Asimismo, mediante un convenio 
suscripto entre la Presidencia de la República y la Universidad, un Equipo de Arqueólogos Forenses inició sus trabajos en predios militares tras la búsqueda de restos o sitios de enterramiento de personas detenidas desaparecidas y otro Equipo de universitarios inició sus trabajos en los archivos del Estado para investigar sobre detenidos desaparecidos en base a la consulta de documentos oficiales.

El resultado del trabajo de arqueólogos, hasta el momento, fue el descubrimiento de restos de dos ciudadanos detenidos desaparecidos enterrados en predios militares. El resultado del trabajo de los historiadores fue la publicación en 4 tomos de la Investigación Histórica sobre Detenidos Desaparecidos de la Presidencia de la República. Esta última investigación fue continuada luego en el marco de la Universidad de la República por un equipo más reducido y el resultado fue la publicación en 3 tomos de la Investigación Histórica sobre la dictadura y el terrorismo de Estado en el Uruguay.

Ahora, entonces, quiero detenerme en algunos de los resultados más salientes de estas dos investigaciones, en tanto constituyen un aporte en dirección a la verdad y justicia sobre el período dictatorial y contribuyen a superar el olvido institucional y el miedo social que pervive sobre nuestro pasado reciente.

Efectivamente, el discurso político dominante en la democracia restaurada trató de reciclar el miedo a la dictadura en el miedo a repetir la historia de los años 1960 y su desenlace: el golpe de Estado. Esa interpretación constituyó una forma de disciplinamiento de la protesta social, de la reinvindicación de verdad y justicia ya que todo lo que se emprendiera en ese sentido iba a desembocar - decían - en la inestabilidad y crisis que provocó la dictadura. Para que esta "lógica" funcionara socialmente se construyó un estereotipo de interpretación del pasado reciente que repetido sistemáticamente durante años logró su memorización y repetición acrítica. A través de ello, no sólo redujo la carga emotiva de la memoria popular y sus héroes (el preso político, el clandestino, el torturado o desaparecido) sino que se obturó la proyección simbólica a futuro de ese pasado y sus ejemplos éticos.

En síntesis, la reescritura de una historia "oficial" desde el poder estructuró una memoria del Estado basada en los secretos del Estado y reproductora de la misma lógica y argumentos conservadores que justificaron 
en nuestro país el gradual ascenso de relaciones autoritarias de poder en el marco de un sistema democrático republicano de gobierno, entre 1967 y 1973.

Los usos de la historia por el discurso del Estado, en vez de centrar la explicación pública en por qué el golpe de Estado y el terrorismo de Estado - lo que siempre remite al Estado y sus agentes como sujetos criminales - recentró su explicación en los años 1960 y en el accionar de los actores no estatales o instituyentes, en particular, los grupos armados de la izquierda (MLN en particular) y el movimiento obrero haciéndolos responsables del golpe por desafiar el orden y a las autoridades legítimamente constituidas a través de la lucha armada y la protesta social.

Los resultados de las investigaciones históricas más recientes también van en contra de esta argumentación dominante, aportando documentación para una reelaboración más democrática de nuestro pasado reciente.

Los equipos universitarios - integrados por 16 y 6 investigadores consultaron un total de 20 archivos estatales y privados, nacionales y extranjeros durante tres años y medio de labor. El aporte principal fue elaborar una historia documentada sobre las múltiples dimensiones que asumió el terrorismo de Estado en el Uruguay, en particular, sobre el fenómeno de la desaparición forzada de personas, demostrar el carácter sistemático, planificado y coordinado a nivel regional de la represión estatal durante casi 12 años y cómo el objetivo de esa represión fue el conjunto de la sociedad uruguaya, no sólo quiénes estaban directamente involucrados en la resistencia u oposición al régimen.

Me voy a referir para concluir mi intervención a la última obra: Investigación histórica sobre la dictadura y el terrorismo de Estado en el Uruguay en tres tomos, que incorpora parte de la investigación realizada anteriormente para la Presidencia de la República sobre detenidos desaparecidos.

En el Tomo l: Las violaciones al derecho a la vida se estudió principalmente el fenómeno del Asesinato Político. El primer apartado contiene las Fichas Personales de 116 ciudadanos asesinados, fallecidos y/o 
autoeliminados en prisión, víctimas del terrorismo de Estado entre 1973 y 1984. También se incorporaron los casos de 8 militares y policiales muertos 0 asesinados en servicio en el mismo período. Se elaboraron cuadros, por ejemplo, con el orden cronológico y las circunstancias de muerte de las personas.

En el apartado sobre Detenidos Desaparecidos se presenta una generalización, sistematización y actualización de los datos contenidos en la investigación histórica de la Presidencia de la República sobre 172 casos estudiados. Se elaboraron cuadros con las modalidades del fenómeno de la desaparición forzada de personas en Uruguay (detenidos desaparecidos, asesinados desaparecidos, NN aparecidos en las costas uruguayas); sobre el momento de la detención; sobre el lugar de detención; y otros. Asimismo, gráficas como, por ejemplo, con los antecedentes policiales o militares de las personas: $25 \%$ sin antecedentes; $27 \%$ con antecedentes ideológicos; $12 \%$ habían sido procesados anteriormente; $6 \%$ con acciones armadas.

En el Tomo II: Las violaciones a la integridad física y la libertad de las personas se estudia el fenómeno de la Prisión Política masiva y prolongada. En base a diversas fuentes oficiales consultadas se elaboró un listado general (incompleto) de 5.925 presos durante la dictadura y se aportan datos sobre las diversas situaciones de detención y 50 centros de reclusión, en particular, sobre el Penal de Libertad (EMR 1). También se estudia la Represión contra las mujeres, el tema de la maternidad y la familia en prisión, los cuarteles y cárceles donde fueron alojadas y los reglamentos disciplinarios del Penal de Punta de Rieles (EMR 2). Entre las situaciones de detención, menciono como ejemplos: las personas liberadas o amnistiadas "al morir" o la documentación sobre el pago de "expensas carcelarias" para ser liberados o sobre el control de las visitas y la vigilancia y seguimiento a los familiares de los presos.

Asimismo, en el Apartado Represión contra las Mujeres nos interesaba comprobar si existió una técnica que tuvo un impacto diferencial en la represión por razones de sexo, en particular, en el tema torturas contra el cuerpo de la mujer y la maternidad en prisión. En ese marco, se elaboró también un listado general de 739 presas políticas.

En otro apartado del $2^{\circ}$ Tomo se da cuenta de la Represión contra los menores de edad y las diversas situaciones por las que atravesaron las 
víctimas: detención y desaparición ( 3 menores al presente), nacimiento en cautiverio, cambio de identidad y apropiación ilegítima, menores presos con sus progenitores (67 casos documentados). También se ilustran las Torturas más comunes a que fueron sometidos los presos políticos y se aportan testimonios de las víctimas.

El contenido del Tomo /l aborda el tema de las violaciones a los derechos civiles ilustrando un aspecto poco documentado aún en las investigaciones sobre el período dictatorial: La vigilancia a la sociedad civil (el "insilio"). Al respecto, se aporta documentación oficial sobre el intento de "control total" de la población por la dictadura: la dimensión cotidiana del terror, la represión a la cultura (censura de libros, cine, teatro, carnaval, música, conferencias, artistas e intelectuales), clausura de medios de comunicación, control de la educación, seguimiento a las actividades religiosas, vigilancia a diversas organizaciones de la sociedad civil (clubes, asociaciones, cooperativas, organizaciones de derechos humanos). Finalmente se incorpora un apartado sobre distintas formas de colaboración de sectores de la población con el régimen dictatorial. En la última sección del presente libro se desarrolla el tema del Exilio, en particular, la vigilancia en el exterior del país a las actividades de solidaridad y a las organizaciones y ciudadanos así como también se ilustra la colaboración entre distintos servicios de inteligencia. Para el régimen fue una preocupación permanente su "imagen internacional". Asimismo se aporta documentación sobre el control, detenciones y expulsiones de Extranjeros residentes en el país, en particular, sobre ciudadanos brasileños. En el Anexo documental se adjuntan listados de asilados uruguayos en la Embajada de México en Montevideo entre 1975-1976 (370 personas en un año) y de uruguayos refugiados en distintos países europeos.

En el Tomo III: Las violaciones a los derechos políticos y sindicales y a la libertad de enseñanza se desarrolla el tema de la Represión a los partidos políticos: organizaciones y grupos de izquierda, Frente Amplio, Partido Colorado y Partido Nacional, en particular a su máximo líder Wilson Ferreira Aldunate. También se aborda el tema de las dimensiones y etapas de la Represión al movimiento sindical y la CNT, reconstruyéndose un listado general de 891 sindicalistas presos durante la dictadura. 
En otro apartado se estudia la Represión a la enseñanza y los estudiantes, en particular, contra la Universidad de la República y la FEUU, la enseñanza secundaria y la Universidad del Trabajo.

Merece particular atención los resultados de la investigación referidos en el Apartado sobre los cambios en la institucionalidad estatal bajo la dictadura, la normativa que aprobaron, la creación o refuncionalización de órganos político-administrativos-diplomáticos que venían del Estado de derecho, el papel de la justicia militar en el juzgamiento y condena a civiles $y$, sobre todo, la configuración de un Estado "clandestino" a través del accionar de los servicios de inteligencia y la coordinación represiva regional.

Finalmente, el Tomo III resume y actualiza los datos referidos a los avances de la sociedad uruguaya desde la recuperación de la democracia en el país (1985) en materia de verdad, justicia, memoria y reparación a las víctimas del terrorismo de Estado. En ese sentido, se repasa la formación de Comisiones investigadoras y los informes oficiales; las leyes aprobadas por el Parlamento y las convenciones y protocolos internacionales incorporados a la legislación nacional; decretos y resoluciones del Poder Ejecutivo; antecedentes, sentencias y autos de procesamiento dictados por la Justicia Penal contra responsables de la violación de los derechos humanos y crímenes de lesa humanidad cometidos bajo la dictadura.

No voy a concluir ahora cómo se relacionan la primera y la segunda parte de mi intervención pero creo que tienen que ver en la reflexión sobre los mecanismos de poder y la continuidad de lógicas autoritarias que trascienden la dictadura como régimen político estatal y se instalan como límite en el presente de toda tentativa de forjar una democracia avanzada en el país. 
